\title{
A Retomada do Debate do Cálculo Econômico Socialista: Economia da Informação, Escolha Pública e a Crítica Austríaca
}

\author{
Fábio Barbieri \\ Professor - Departamento de Economia (FEA-USP/RP) \\ Endereço para contato: Av. Bandeirantes, 3900 - Monte Alegre \\ Ribeirão Preto - SP - CEP: 140040-905 \\ E-mail: fbarbieri@usp.br
}

Recebido em 21 de setembro de 2011 . Aceito em 27 de março de 2012.

\begin{abstract}
Resumo
Este artigo analisa a moderna retomada do debate do cálculo econômico socialista. Mostramos como as modificações no cinturão protetor do programa de pesquisa neoclássico possibilitaram a discussão do problema dos incentivos sob informação assimétrica nas novas propostas de socialismo de mercado. Nessas propostas, o problema do conhecimento tal como desenvolvido por Hayek no debate original será interpretado como um problema de informação. Defendemos a tese de que, embora os modelos tenham sido criticados por economistas afiliados a escola da escolha pública, as novas propostas de socialismo de mercado e seus críticos sofrem dos mesmos problemas apontados por Hayek no debate original.
\end{abstract}

\section{Palavras-Chave}

planejamento central, microeconomia, economia da informação, escola austríaca

\begin{abstract}
This article examines the modern revival of socialist economic calculation debate. We show how changes in the protective belt of neoclassical research programme enabled the discussion of the problem of incentives under asymmetric information on the new proposals for market socialism. Under these proposals, the problem of knowledge as developed by Hayek in original debate will be interpreted as an information problem. We contend that, although the models were criticized by Public Choice economists, the new proposals and their critics both suffer from the same problems pointed out by Hayek in the original debate.
\end{abstract}

\section{Keywords}

central planning, microeconomics, economics of information, Austrian school

\section{JEL Classification \\ B21, B53}

\footnotetext{
- O autor agradece os comentários e sugestões dos pareceristas anônimos.
} 


\section{Introdução}

Parte do fascínio exercido pelo debate do cálculo econômico socialista advém do contraste entre programas de pesquisa diferentes: na controvérsia, a economia do socialismo foi discutida sob os pontos de vista marxista, neoclássico e austríaco, o que permitiu que surgisse uma vasta literatura secundária sobre a natureza do problema debatido. ${ }^{1}$ A maioria dessa literatura, porém, trata quase que exclusivamente da discussão dos modelos de socialismo de mercado (SM) da década de trinta. O debate do cálculo, porém, é mais amplo. Seu início pode ser identificado com a antecipação do argumento de Mises feito por Gossen ${ }^{2}$ na metade do século dezenove e prossegue até os modelos de SM propostos na década de noventa do século vinte. Essa longa duração permite então que exploremos não apenas o contraste entre programas de pesquisa rivais, mas também o modo como as alterações ao longo do tempo no cinturão protetor de um desses programas molda aquilo que é considerado legítimo ou não discutir (as heurísticas positivas e negativas, no referencial lakatosiano).

Neste artigo analisaremos como uma nova geração de propostas de SM surgiu a partir de considerações sobre um desses desenvolvimentos da teoria neoclássica - a Economia da Informação. Depois de examinar os novos modelos de SM, veremos como os mesmos foram criticados sob o ponto de vista da escola da Escolha Pública. Constataremos que o aspecto marcante dessa nova fase do debate é a centralidade da questão dos incentivos, ponto este excluído do debate original. Antes de investigar como as alterações no cinturão protetor da teoria neoclássica permitiram a legitimação do estudo dessas questões, e como estas resultaram em novos modelos de SM, debruçaremos sobre a rejeição, por parte dos novos debatedores, do problema do conhecimento proposto por Hayek no programa de pesquisa austríaco, na medida em que a aceitação desse problema afetaria o núcleo duro do primeiro programa. Estabelecida essa tese,

1 Para aqueles não familiarizados com o debate do cálculo, existem vários textos que retratam e analisam sua história. Ver, por exemplo, Soto (1992), Lavoie (1985) e Barbieri (2004). Para uma introdução a abordagem austríaca, ver Soto (2010).

2 Gossen (1983:254) afirma: "Moreover, only with the establishment of private property can the yardstick be found for the determination of the optimal quantity of each commodity to be produced under given circumstances. This follows from the previously found laws of pleasure and the related rise and fall in the value of any commodity... and the manner by which prices are determined. Consequently, the central authority - projected by the communist - for the purpose of allocating the different types of labour and their rewards would soon find that it has set itself a task that far excess the powers of any individual (ênfase no original). 
teremos condições de afirmar que - a nossa tese principal - a despeito dessa rejeição, os novos modelos sofrem das mesmas críticas feitas por Hayek aos modelos da primeira geração, já que ignoram o problema do conhecimento.

\section{Os Problemas do Conhecimento e de Informação Assimétrica}

O debate do cálculo na década de trinta excluía qualquer consideração a respeito dos problemas de incentivos no socialismo. Da parte dos austríacos, a omissão desse problema pode ser explicada pelo fato de que os economistas austríacos pretendiam colocar uma nova objeção ao funcionamento de uma economia socialista: mesmo havendo boa intenção e motivação, a falta de um sistema de preços de mercado que sinalize escassez relativa impede o conhecimento sobre as vias de ação mais econômicas. Da parte dos economistas neoclássicos, porém, a proposição austríaca segundo a qual a propriedade privada seria necessária para o funcionamento dos mercados foi interpretada justamente como uma questão de incentivos. Mas, para os economistas neoclássicos do período, a análise puramente econômica do socialismo deveria excluir qualquer consideração sobre incentivos.

Para Frank Knight (1936), por exemplo, defensor do mesmo apriorismo metodológico de Mises, a teoria econômica trata apenas da comparação entre valores dos usos alternativos dos recursos quando há escassez. Qualquer outro tipo de consideração, como o problema dos incentivos, fugiria do escopo da teoria econômica pura, sendo de natureza histórica. Lerner, por sua vez, explicitamente exclui os incentivos da análise econômica, relegando o problema a estudos sociológicos. ${ }^{3}$

Barrada a discussão sobre incentivos, os socialistas de mercado desenvolveram propostas de socialismo compatíveis com o estágio de desenvolvimento do programa de pesquisa neoclássico, procurando recriar economias que replicassem a descrição teórica de um equi-

\footnotetext{
3 Knight (1936:256) escreve: "This means - and this is the main point to be made in the present paper - that the problems of collectivism are not problems of economic theory, but political problems, and that the economic theorist, as such, has little or nothing to say about them". Lerner (1937: 269), por seu turno, afirma: "The question is then the sociological one, whether the Socialist Trust is able to estimate this future value more accurately or less accurately than the competitive owner of the hired instrument, and here we leave pure economic theory."
} 
líbrio competitivo. Os austríacos, por sua vez, chamaram a atenção para a insuficiência dessa descrição do equilíbrio para a compreensão do fenômeno da competição, que deveria ser vista como um processo. Isso, como é bem sabido, marca a percepção de que a tradição austríaca constitui um programa de pesquisa distinto do neoclássico. Nesse programa, o "problema do conhecimento" proposto por Hayek é crucial para o debate: a teoria econômica deve explicar como o conhecimento falível e disperso dos agentes se aproxima ou não dos fundamentos corretos da economia em vez de considerar tais fundamentos dados desde o início da análise. ${ }^{4}$ Esse processo de aprendizado é explicado pelos austríacos, em última análise, por meio de um modelo evolucionário de aprendizado: ${ }^{5}$ a competição nos mercados é vista como um processo rival de aprendizado que supõe inicialmente tanto a liberdade para a ação empresarial experimentar novas soluções (variações) quanto um mecanismo de correção de erros (seleção) imposto pela lucratividade dos projetos. Nos modelos de SM, por exemplo, as firmas não poderiam seguir a regra de igualar os preços paramétricos aos custos que prevaleceriam em competição perfeita porque o conhecimento a respeito das formas mais baratas de produzir não é dado, mas é descoberto através do processo rival de competição fora do equilíbrio, que é barrado pelo modelo.

Com a evolução do programa de pesquisa neoclássico em meados do século vinte, o pressuposto de conhecimento perfeito foi substituído pela noção de ignorância ótima em ambiente de risco, preservando-se o pressuposto central de maximização de funções conhecidas, agora adaptado para ganhos esperados. Posteriormente, com o desenvolvimento da Economia da Informação, a teoria econômica teve condições de explicar uma série de problemas interessantes derivados da existência de assimetrias de informação. Em termos lakatosianos, essas alterações no cinturão protetor do programa caracterizam evolução progressiva do mesmo. Sendo assim, é natural que o debate do cálculo seja retomado à luz dessas alterações, como de fato ocorreu.

Essa reavaliação, por envolver novamente o choque entre programas de pesquisa com proposições nucleares rivais, resultou na interpretação do problema do conhecimento de Hayek como se fosse um problema de informação assimétrica. Para Hayek ${ }^{6}$ (1980), o

\footnotetext{
4 Ver os artigos reunidos em Hayek (1980).

5 Ver Bartley e Radnitsky (1987).

${ }^{6}$ Nessa coletânea, ver em especial os artigos intitulados "Economics and Knowledge", "The
} 
valor do sistema de preços como um mecanismo de transmissão de informação se manifesta sobremaneira fora do equilíbrio. Dada a presença simultânea da (a) progressiva complexidade da divisão do trabalho que acompanha o processo de mercado e do (b) conhecimento limitado de cada agente, é natural que antes do equilíbrio as crenças de cada agente sobre os fundamentos da economia (preferências, tecnologias e recursos) e sobre os planos dos demais agentes sejam inconsistentes. Em outros termos, o conhecimento empresarial é falível. Sendo assim, o sistema de preços, por meio do cálculo de lucros e prejuízos, atua como um teste das diferentes conjecturas empresariais dos agentes, guiando e corrigindo essas conjecturas, ${ }^{7}$ o que pode ser interpretado em termos evolucionários, como aludido acima. Como os fundamentos da economia se alteram continuamente, essa 'força equilibradora' não resulta em um equilíbrio: para Hayek, o mercado é valorizado em termos de sua capacidade de adaptação a essas mudanças e não em termos da obtenção de equilíbrios eficientes.

Grossman e Stiglitz (1996), no entanto, interpretam o argumento hayekiano somente em termos da teoria de equilíbrio. Para os autores, Hayek teria afirmado, de forma errônea, que em equilíbrio os preços transmitem informação de forma eficiente. Se fosse assim, argumentam os autores, valeria a pena para alguns agentes não investir em informação custosa e pegar carona na informação contida nos preços. Ocorrendo isso, os preços não transmitem informação de forma ótima. ${ }^{8}$ Vejamos um exemplo: em vez de investir em prognósticos metereológicos, o investidor no mercado de laranja poderia observar apenas o preço da mercadoria - um preço em elevação indicaria que outros agentes que fizeram o investimento em pesquisa acreditam em quebra de safra. Observando apenas o preço, nosso agente desinformado pode comprar sem incorrer nos custos da pesquisa. Mas se isso for verdade, mais agentes não se informarão até que no limite o preço deixe de refletir informação mais apurada. Portanto, como existe externalidade informacional nos preços, o preço de equilíbrio não pode conter toda a informação necessária para a tomada de decisões, como teria afirmado Hayek, na interpretação dos autores.

\footnotetext{
Uses of Knowledge in Society" e The Meaning of Competition". Ver também Hayek (1978).

7 Para exemplos dessa interpretação das ideias hayekianas, ver Thomsen (1992) e, em português, Barbieri (2006).

8 Para uma crítica dessa interpretação das ideias de Hayek, ver Thomsen (1992).
} 
Com essa interpretação do significado das ideias de Hayek, os novos analistas do SM puderam ignorar as objeções aos modelos do debate original feitas em termos da teoria de processo de mercado, caracterizando a discussão inteiramente nos termos do programa neoclássico. Isso possibilitou a crença de que o defeito de tais modelos consiste exclusivamente na ignorância dos problemas de informação assimétrica:

Thus in our view the Lange-Lerner-TaylorHayek debate comes down to the fundamental distinction between economies where: (1) prices and hence allocations are the outcome of a competitive arbitrage process which will, of necessity, be imperfect because of the costs of arbitrage as discussed in this paper, and (2) economies where prices and hence allocations are the outcome of a centralized allocative mechanism which will, of necessity, be imperfect because of the costs of monitoring bureaucrats. (Grossman e Stiglitz, 1996:252)

Diante desse diagnóstico, a nova geração de modelos conterá mecanismos de incentivos que visam lidar com problemas de incentivos no SM.

O desenvolvimento desses modelos, no entanto, não foi motivado apenas pela evolução da teoria. A crise do socialismo real também foi importante na retomada do debate. Um dos principais advogados do SM moderno, Roemer (1994, p. 7), acredita que o principal motivo para o fracasso das economias planejadas centralmente foi a falha em resolver problemas do tipo agente-principal. Os socialistas de mercado da nova geração, além disso, foram influenciados pela crítica de Kornai (1986) às economias do leste europeu. Para esse autor, os problemas econômicos dessas economias seriam derivados daquilo que denomina "síndrome de restrição orçamentária tênue", ou seja, o relaxamento financeiro resultante da expectativa existente nas firmas de que, se fracassarem, serão socorridas pelo estado por meio de assistência financeira. Esse diagnóstico também motivou a investigação do problema de monitoramento de firmas socialistas segundo a abordagem de informação assimétrica. Vejamos então como o moderno SM lida com o problema dos incentivos. 


\section{A Nova Geração de Modelos de Socialismo de Mercado}

Para os modernos socialistas de mercado da década de noventa, o problema toma a forma do desenho de instituições que forneçam os incentivos para que os agentes sigam as instruções dos principais na presença de informação assimétrica. Para esses economistas, a síndrome identificada por Kornai foi de fato vista como uma manifestação desse problema de agência: sem um mecanismo crível de incentivo ou punição por meio dos lucros e perdas as firmas não seguem a ordem que as obrigaria a maximizar lucros. As propostas mais modernas de socialismo de mercado irão então buscar formas alternativas de lidar com esse problema sem que se apele para a restauração completa da propriedade privada. Vejamos um esboço de cada modelo, cada um deles buscando lidar com o problema de agência identificado como central ao SM.

\subsection{Modelo de Roemer}

Em comparação com os modelos originais, Roemer (1993:7) nota que as novas propostas de socialismo de mercado irão abandonar não só a necessidade de fixação central de preços, presente no modelo de Lange, como também a própria noção de propriedade pública (estatal) dos fatores produtivos. O novo socialismo de mercado dá então um passo além da proposta de Durbin, que não fixava centralmente os preços, mas retinha a propriedade pública dos fatores. ${ }^{9}$ Com essa concessão, contudo, poucos estariam inclinados a conceder credenciais socialistas a essas propostas. De fato, tanto defensores quanto oponentes do socialismo ao longo do debate original consideraram a propriedade pública como o caráter central do socialismo. Roemer lida com esse problema notando que além da propriedade privada ou estatal pura, existem inúmeras formas de direitos de propriedade intermediárias que poderiam ser utilizadas como instrumentos para se obter fins socialistas.

A fim de atingir esses objetivos, o socialismo deveria utilizar a capacidade dos mercados de induzir os administradores a maximizar lucros, de forma a gerar alocações eficientes sob competição. Isso, porém, deve ser dissociado da distribuição de renda desigual que

9 Nessa proposta de SM, cada setor da economia seria operado por uma firma estatal monopolista que fixa ela própria preços iguais ao custo médio mínimo. Nesse sentido, esse modelo envolve menos centralização do que a determinação centralizada de preços proposta por Lange. 
caracteriza o capitalismo. A fim de extrair tal vantagem sem a consequência distributiva indesejável, Roemer imagina o modelo esboçado em seguida.

O problema de agência na proposta de Roemer é resolvido por meio da introdução de uma bolsa de valores no socialismo. Cada cidadão adulto teria direito a um conjunto de vales correspondentes a uma fração do capital de cada firma grande do país. Na prática, Roemer (Bardhan e Roemer, 1992:110; 1993:96; 1994:49) imagina uma série de fundos mútuos detentores de portfólios idênticos de ações de todas as firmas, e cada habitante adulto por sua vez possuiria ações dos fundos mútuos. Quando um indivíduo morre, suas ações voltam para o estado, que as distribui entre aqueles que adquirem maioridade.

A partir dessa situação inicial a bolsa de valores funcionaria de forma a equilibrar o valor das ações das firmas. A fim de que os pobres não vendam seus ativos aos ricos ou aos mais informados, o que restabeleceria a desigualdade de direitos ao rendimento do capital, limitam-se os direitos de propriedade sobre os papéis: os indivíduos seriam proibidos de vender todos os seus ativos financeiros; as ações só podem ser trocadas por outras. Tampouco poupanças acumuladas em dinheiro podem ser usadas para adquirir ações. Estabelece-se assim uma espécie de escambo de ações: a moeda corrente não serve como meio de troca nesses mercados. Embora não se possam obter ganhos com a troca de ações por dinheiro, os detentores das ações teriam direito aos lucros do capital representados pela ação.

O financiamento de investimentos ocorreria via empréstimos bancários. Roemer imagina bancos ligados a um conjunto de firmas associadas, cujos quadros de diretores seriam formados por representantes dos fundos mútuos e do banco financiador.

As firmas menores poderiam ser criadas e operadas de forma tradicional, com propriedade privada plena, o que garante a continuidade das inovações. A partir de certo tamanho, contudo, as firmas pequenas sobreviventes teriam que participar do esquema proposto acima, sendo nacionalizadas.

Retendo uma característica comum ao socialismo de mercado original, propõe-se que o estado possa dirigir o investimento, seja de forma direta, seja manipulando taxas diferenciadas de juros. A jus- 
tificativa moderna, porém, baseia-se na ideia de falhas derivadas de mercados incompletos de capital.

Com a sua proposta, Roemer pretende ao mesmo tempo resolver o problema de agência e garantir uma distribuição igualitária no socialismo de mercado. Se os preços (expressos em vales) das ações de uma firma caírem, os fundos mútuos irão vender seus estoques. $\mathrm{O}$ banco financiador e os fundos mútuos terão então incentivos para monitorar o desempenho das firmas. Nas economias de mercado, a pressão para manter o desempenho econômico é acompanhada por variações na riqueza dos agentes. No socialismo de mercado de Roemer, porém, pretende-se quebrar essa relação:

I am assuming that the mechanism of requiring citizens to hold shares of mutual funds, and not firms directly, would prevent the unworldly from losing their stock assets by making poor investments. There would have to be federal regulation of the mutual funds. (Roemer, 1993:97)

Como sugere a última frase da citação, na verdade o problema reaparece uma instância acima: como monitorar os monitores? Com isso chegamos aos problemas que foram o foco da análise de Kornai. Embora reconheça que não se possa fugir completamente do problema da restrição orçamentária tênue, Roemer acredita que os bancos e fundos mútuos formam uma camada protetora entre as firmas e o tesouro, já que os monitores teriam uma reputação a zelar. (Bardham e Roemer, 1994:77)

\subsection{Modelo de Bardhan}

A apresentação da proposta de Roemer foi acompanhada por uma variante defendida por Bardhan. Este último interpreta o problema da restrição orçamentária tênue como constituído de duas partes: o problema de agência na administração das firmas e o problema político de compromisso crível por parte do estado de se ater às regras. Para resolver o primeiro problema, o autor propõe (Bardhan e Roemer, 1992:108; 1993:147) uma forma de socialismo de mercado na qual as firmas são sociedades de capital aberto com algumas 
ações pertencentes aos seus trabalhadores, instituições financeiras, fundos de pensão e governos locais, entre outros. A maioria das ações seria controlada pelas demais firmas pertencentes ao mesmo grupo e ao banco associado ao mesmo. Cada grupo de firmas estaria então associado a um banco principal.

O financiamento do capital das firmas seria feito pelos bancos principais, cujo sócio majoritário seria o governo central. Cada grupo não pode ser muito grande, de forma a que se perca a capacidade de monitoramento por parte do banco, mas também não pode ser pequeno, devido ao aumento do risco associado a um portfólio dependente de poucos empreendimentos. Como na proposta de Roemer, pequenos empresários seriam livres para criar e operar pequenas empresas de forma independente.

O socialismo de mercado proposto por Bardhan difere do de Roemer essencialmente no que diz respeito às instituições responsáveis pelo monitoramento da administração das firmas. Enquanto na proposta deste último tal tarefa seria realizada através de uma bolsa de valores, na proposta do primeiro autor temos o controle centrado em bancos, inspirados no sistema financeiro japonês. Na opinião do autor, grupos financeiros como os keiretzus japoneses possibilitariam um monitoramento mais direto das firmas do que a ameaça de aquisição em uma bolsa de valores, pois a concentração da propriedade nos bancos resultaria no maior interesse da parte dos administradores do banco na fiscalização das firmas e na obtenção de informações sobre as mesmas do que acionistas dispersos.

O monitoramento das firmas assumiria a seguinte forma:

The shares of a large firm can be sold to the main bank. At the first signs of significant attempts by other firms at unloading the shares of a particular firm, and usually much earlier, the main bank will take measures to prod and discipline the management, renegotiate the debt contract if necessary, orchestrate financial rescue strategies, help the firm with an interest moratorium and emergency loans, an arrange for technological assistance from affiliated firms and for the (temporary) sale of the firm's stock assets (in other firms) to cover its ope- 
rating losses. ... it [the bank] will even have the power to take over temporarily the management of the ailing firm, if necessary. (Bardhan e Roemer, 1993:148)

Os bancos, além de sua capacidade de resolver o problema de agência das firmas, estariam menos sujeitos ao comportamento miópico encontrado nas bolsas, voltado para a lucratividade de curto prazo.

\subsection{Modelo de Fleurbaey}

Na mesma coletânea editada por Bardhan e Roemer podemos encontrar a proposta de SM com firmas administradas pelos trabalhadores. Para Fleurbaey (1993: 274), as versões tradicionais de SM focam no objetivo de obter melhor distribuição de renda, negligenciando o objetivo socialista de atingir uma maior democracia no local de trabalho, objetivo este perseguido em sua proposta.

Nesta, pretende-se alterar os direitos de propriedade de forma a separar três poderes que podem ser exercidos pelos mesmos agentes no sistema de propriedade privada: a decisão sobre a proporção entre consumo e investimento, a decisão sobre a alocação de capital para firmas e a decisão sobre o uso do capital dentro da firma.

Este último permaneceria sob a responsabilidade dos trabalhadores. As decisões administrativas seriam tomadas de forma democrática, via consulta aos trabalhadores. O autor, porém, não explicita em sua proposta a forma de participação adequada, que poderia variar desde o extremo no qual cada decisão administrativa deva ser votada pelos trabalhadores até a delegação da autoridade a administradores profissionais por períodos determinados de tempo via eleições, passando pela rotação dos trabalhadores nos cargos gerenciais.

As decisões do segundo tipo, por sua vez, seriam totalmente delegadas aos bancos. As famílias decidem a proporção de sua renda a ser poupada, depositam sua poupança nos bancos, que emprestam o capital às firmas interessadas. Todo o financiamento assume essa forma, sendo proibidos mercados de capital nos quais as famílias financiem diretamente as firmas via ações e outros títulos. Na proposta do autor, sequer as firmas poderiam se autofinanciar. Embora não seja discutido neste ponto o destino dos lucros extraordinários, 
podemos inferir que estes seriam automaticamente distribuídos aos trabalhadores da firma. Os bancos, por sua vez, poderiam ser firmas públicas ou privadas, todas elas administradas pelos trabalhadores. Pressupõe o autor que tais bancos competirão entre si na captação de recursos e financiamento das firmas, de forma intensa o bastante para que o problema de agência entre o público e os bancos (má administração dos portfólios) seja mitigado.

A redistribuição da renda, já que nesse esquema há a tendência de se afastar de uma distribuição igualitária, poderia ser realizada sem o uso de tributação, na mudança de gerações, impondo-se um limite ao montante que uma pessoa possa herdar, limite esse próximo da riqueza média per capita. Finalmente, imagina o autor, haveria a adoção de planejamento indireto via impostos e subsídios para correção de externalidades ou para direcionamento do investimento em certas direções.

$\mathrm{Na}$ proposta descrita acima, Fleurbaey pretende, com o financiamento de firmas por bancos, contornar alguns problemas identificados com os demais modelos de economias com firmas geridas pelos trabalhadores. Sem financiamento externo, as firmas tenderiam a investir menos do que o ótimo, por uma série de razões: os horizontes de vida dos projetos são maiores do que o tempo de trabalho futuro dos trabalhadores atuais; os trabalhadores novos 'pegariam carona' nos investimentos antigos e os trabalhadores seriam muito expostos ao risco, porque investem seu capital e trabalho em um mesmo empreendimento. Ao apelar para o financiamento externo via uma rede de bancos, tais problemas seriam contornados: o pagamento dos empréstimos pode ser simultâneo com os retornos do projeto, os novos trabalhadores também pagam as amortizações dos empréstimos e os bancos funcionam como seguradoras para os trabalhadores, cujo capital financeiro é investido em uma carteira diversificada de ativos. Além de seu papel de seguradora, Fleurbaey acredita, como Bardham, que os bancos teriam capacidade superior de monitorar a administração das firmas do que acionistas. 


\subsection{Modelo de Weisskopf}

Embora a proposta de Fleurbaey contemple em alguma medida os problemas de agência tratados por Bardham e incorpore o financiamento das firmas por uma rede de bancos, temos ainda na nova geração de modelos de socialismo de mercado uma proposta mista, que combina elementos do socialismo de mercado com mercado de capitais de Roemer e elementos do socialismo de mercado baseado em administração pelos trabalhadores. Weisskopf (1993) imagina um socialismo que evite os problemas tanto do SM tradicional (problemas de informação assimétrica) quanto da administração por trabalhadores (falta de investimentos, falta de mercados de trabalho desenvolvidos e risco elevado para os trabalhadores), preservando, contudo, suas respectivas vantagens (relativa igualdade de renda e democracia nas decisões econômicas, respectivamente).

Nesse modelo híbrido, as firmas com mais de dez trabalhadores elegem conselhos a partir de eleições, com um voto por trabalhador. $\mathrm{O}$ conselho, por sua vez, contrata administradores das firmas, responsáveis pela gestão das firmas. Firmas pequenas, por sua vez, podem existir sob o regime de propriedade privada convencional.

O financiamento das firmas administradas pelos trabalhadores é realizado por aluguel de ativos de outras firmas, por empréstimos bancários junto a instituições financeiras administradas pelos trabalhadores, por emissão de ações sem direito a voto ou reinvestindo os lucros retidos. Consequentemente, os ofertantes externos de capital teriam influência apenas indireta sobre as decisões das firmas, que ficam sob a responsabilidade dos administradores que respondem aos trabalhadores.

Ao contrário da proposta de Roemer, na qual os proprietários das ações podem influenciar diretamente as decisões das firmas, no modelo de Weisskopf existe um mercado de ações sem direito a voto e um mercado no qual ações de fundos mútuos são distribuídas equitativamente à população adulta, que não pode trocá-las por outras formas de ativos, da mesma forma como imaginado por Roemer. A diferença entre as duas propostas garantiria assim um maior controle da administração pelos trabalhadores. 


\subsection{Modelo de Yunker}

A última proposta moderna de socialismo de mercado que destacaremos foi sugerida por Yunker (1995). Em sua proposta, uma agência central denominada Bureau of Public Ownership (BPO) apropriarse-ia de todos os ativos financeiros previamente possuídos pelas famílias. Os ativos pertencentes a pessoas jurídicas, por outro lado, permaneceriam com seus donos. Entretanto, as ações com direito a voto seriam convertidas em títulos sem esses direitos, que seriam totalmente controlados pelo BPO.

O BPO nacional seria descentralizado em escritórios regionais, cada um deles contendo agentes recrutados entre administradores de empresas. A cada agente seriam atribuídas as funções dos acionistas de um conjunto de empresas de setores não relacionados entre si, para evitar conluios anticompetitivos. $\mathrm{O}$ agente do $\mathrm{BPO}$ não poderia interferir nas decisões administrativas, mas apenas aprovar o plano de pagamento dos executivos das firmas, aprovar a nomeação do executivo-chefe e decidir sobre a demissão ou manutenção desse executivo.

O salário do agente do BPO seria uma fração bem pequena dos lucros das firmas sob sua responsabilidade. Os ativos financeiros nessa economia seriam por sua vez indicadores de desempenho e não fonte de rendimento de capital. Pretende-se assim uma economia guiada por mercados, mas sem a concentração de renda derivada da posse de capital - combinação almejada por todas as formas de socialismo de mercado modernas.

Como nas propostas anteriores, firmas pequenas e profissionais liberais poderiam operar de forma independente. Yunker permitiria ainda a existência de firmas grandes livres do controle pelo BPO, desde que administradas pelos seus donos fundadores. Neste caso, seria cobrado um imposto sobre o capital igual à taxa normal de retorno do capital da economia.

Além do objetivo socialista de obter maior igualdade de renda, Yunker busca maior eficiência. A centralização do controle no BPO, para o autor, resolveria o problema de incentivo advindo da separação entre posse e controle dos ativos, pois o risco de demissão do executivo-chefe seria maior. Além disso, os rendimentos do capital 
seriam distribuídos aos trabalhadores como um percentual fixo do salário.

Tomando em conjunto todas as variantes do moderno SM, podemos de fato constatar a percepção de seus autores a respeito da centralidade que o problema de incentivos ocupa no que diz respeito à economia do socialismo. Essa centralidade foi motivada tanto pela discussão empírica sobre os problemas econômicos das economias do leste europeu, em especial a 'síndrome de restrição orçamentária tênue', quanto pelo desenvolvimento da teoria econômica que possibilitava a interpretação desses problemas à luz da teoria da informação assimétrica. Esse diagnóstico levou naturalmente a proposta de desenhar mecanismos de incentivos para resolver o problema, ignorado pela geração original de modelos.

\section{A Nova Geração de Críticas}

Consideremos novamente a evolução do debate do cálculo como um todo. A primeira geração de socialistas de mercado foi criticada pelos austríacos em termos da incapacidade da teoria pura de equilíbrio de resolver o problema do cálculo. Defensores e críticos, contudo, não discutiram os pressupostos sobre motivação dos agentes no SM. Com o desenvolvimento da teoria da informação assimétrica, uma nova geração de socialistas de mercado procurou lidar justamente com o problema da motivação, ainda sob o ponto de vista de teoria de equilíbrio. Da mesma forma, os críticos dos novos modelos comungarão com os defensores do novo SM os pressupostos da teoria de equilíbrio e a preocupação com a motivação dos agentes. A crítica, como veremos agora, será baseada na adição de considerações sobre a motivação dos políticos e funcionários públicos.

Como acontecera anteriormente com novos socialistas de mercado, os novos críticos do SM também traduzirão os argumentos austríacos empregados no debate original em termos do próprio programa de pesquisa. De fato, Shleifer e Vishny (1994:166-167) resumem o debate do cálculo de forma idêntica a como isso é feito pelos socialistas de mercado, isto é, em termos da capacidade de replicar equilíbrios de mercado eficientes. Em outro trabalho, Shleifer e Vishny (1992:246) caracterizam o debate como uma discussão sobre a 'complexidade da tarefa computacional enfrentada pelo planejador 
benevolente'. Levy (1990), por sua vez, ao tentar buscar sem sucesso no artigo original de Mises o argumento sobre as reais intenções dos planejadores, procura ler no argumento original desse autor apenas objeções à capacidade de encontrar preços de equilíbrio que melhor estimem os produtos marginais dos fatores em equilíbrio.

Com a tradução do argumento austríaco para o referencial neoclássico, desaparece novamente qualquer objeção ao SM que possa ser feito em termos da teoria de processo de mercado: equilíbrios eficientes poderiam ser encontrados se planejadores centrais desinteressados ditassem regras às firmas socialistas. O SM (antigo e moderno), porém, fracassaria se o pressuposto de agentes públicos benevolentes for contestado, como faz a Escola da Escolha Pública.

Essa nova abordagem crítica não causa surpresa. Afinal, os socialistas de mercado antigos e modernos procuraram resolver um dos problemas atribuídos às economias de mercado - a monopolização - por meio de esquemas que apelam de uma forma ou outra para a imposição de monopólios legais (seja de firmas, seja de órgãos de financiamento ou ainda de comitês centrais). Isso convida naturalmente ao questionamento sobre o que garantiria que os gerentes de um monopólio legal puro se comportem de forma superior aos gerentes em uma economia com apenas certo grau de monopolização.

Para Shleifer e Vishny (1994:167), o argumento de Lange de que o socialismo de mercado poderia alocar recursos de forma mais eficiente do que os mercados reais dependeria do pressuposto de que os governos de fato buscam a obtenção de maior eficiência. Os objetivos distributivos, de internalização de externalidades e de eliminação do poder de monopólio só seriam buscados de fato se o governo se preocupasse com esses problemas.

Mas, apontam os autores, no socialismo real podemos observar que bens escassos não têm seus preços elevados, o grau de concentração industrial é maior do que nas economias de mercado, o grau de poluição também é maior e não ocorrem inovações advindas de mais competição. Isso seria explicado pela hipótese de que os governantes não têm como objetivo a maximização do bem-estar, mas sim do seu próprio interesse. Sendo esse o caso, as tentativas modernas de prover o socialismo de mecanismos de incentivos parecidos com os de mercado, como no sistema bancário proposto por Bardhan e Roemer, 
seriam fadadas ao fracasso. Os interesses dos políticos destruiriam qualquer esquema no qual firmas de fato obtivessem lucros.

Por isso, para os autores, mais importante do que os incentivos dos agentes são os objetivos dos principais:

... market socialists often obfuscate the importance of politician's intentions by imagining complex corporate governance structures. Thus Bardhan and Roemer imagine a system in which the government controls banks, which also have other shareholders, and that in turn control enterprises. Our view in this issue is simple, but realistic: no matter what smoke and mirrors are used, as long as the government remains in ultimate control of enterprises, which it does by definition in all market socialists' schemes, its objectives are going to be the ones that are maximized. Any manager who dares to stand up to the government, or to the bank controlled by the government, will be acting against personal interests. Similarly, no manager of a bank controlled by the government will refuse to lend money to a large state enterprise when the government that hired him "advises" in favor of the loan. (Shleifer $e$ Vishny, 1994:170)

Para os autores, um ditador de um país socialista totalitário, livre de pressões políticas, poderia em princípio agir de forma a garantir eficiência, visto que ele seria em última análise o proprietário de todos os ativos da economia e seu interesse seria então maximizar o produto total. Contudo, tal ditador não opera em um ambiente competitivo: o mais provável seria a manipulação de preços para a extração de ganhos de monopólio, e não a busca da eficiência econômica. Por outro lado, se o ditador maximizador de riqueza sofresse pressões políticas, o resultado seria ainda menos eficiente. Nesse caso predominaria a construção de monumentos, exércitos, concessão da administração das firmas a conhecidos em detrimento de especialistas, industrialização fracassada, com firmas gigantes e ineficientes, mas como grande poder propagandístico e assim por diante. 
Se a hipótese de políticos autointeressados for válida, como os preços seriam ajustados no socialismo? Ao contrário do governo desinteressado de Lange, que ajusta os preços de forma a igualar oferta e demanda, um governo maximizador de renda tenderia a fixar preços abaixo do equilíbrio, de forma a gerar escassez, como de fato seria observável no socialismo real. Enquanto Kornai explica a constante falta de produtos pelo fenômeno da restrição orçamentária tênue as firmas adquirem todos os insumos que puderem, visto que não se importam com o custo - os economistas da escola da Escolha Pública explicam o mesmo fenômeno como uma maneira de coletar subornos.

Para Levy (1990:217), se o preço de um produto for fixado abaixo do equilíbrio competitivo, a diferença entre disposição a pagar (lida na curva de demanda) e preço controlado representa o máximo que um consumidor estaria disposto a pagar 'por fora' para obter o produto que, multiplicado pela quantidade transacionada, resulta no montante do suborno arrecadado. O responsável por cada produto zelaria pela existência da escassez de seu produto, de forma a poder trocar o direito de compra pelos outros bens da economia. Teríamos então sistematicamente uma produção abaixo da quantidade eficiente prevista por Lange.

Shleifer e Vishny (1992) desenvolvem essas ideias. Se os impostos sobre os lucros das firmas socialistas forem próximos de $100 \%$, como seria o caso nas economias socialistas, os gerentes das firmas não teriam interesse em vender ao preço de equilíbrio. Se uma escassez for mantida por meio de um preço baixo, a diferença apontada acima pode ser coletada como suborno, não sujeito a confisco. Os autores supõem que não há competição entre firmas, caso contrário poderia haver redução competitiva dos subornos a zero. No modelo, porém, as firmas em uma indústria seriam coordenadas pelos responsáveis pela indústria, que participariam dos ganhos com o suborno.

O objetivo das firmas seria então maximizar o suborno. A receita total seria dada pela arrecadação do suborno mais a receita oficial. Como os insumos são pagos pelo estado de qualquer modo, os custos de produção não aparecem na função. Para a firma os custos unitários são representados pelo próprio preço controlado, já que a receita é confiscada pelo governo. A maximização do suborno líquido resulta na familiar condição de receita marginal igual ao custo marginal; no 
caso, o preço oficial. Totalmente não restrita, a indústria gostaria de fixar o preço em zero e produzir enquanto a receita marginal for positiva. Isso, contudo, aumentaria os problemas orçamentários do estado. Este poderia então impor um limite mínimo para os lucros ou aumentar os preços.

No primeiro caso, a maximização deve levar em conta a restrição de que a receita total menos os custos de produção sejam iguais ao montante do lucro mínimo. Levando em conta essa restrição, a firma produz de forma a igualar custos marginais com receita marginal. Teríamos então firmas produzindo a quantidade de monopólio, independente da restrição de lucro mínimo. Isso significa que deixar a restrição orçamentária menos tênue reduziria a escassez via aumento de preços e não de produção. No segundo caso, se o preço oficial aumentar, teremos o surpreendente resultado de que a quantidade produzida diminui ainda mais, pois o 'custo' marginal (isto é, o preço controlado) aumentou. Nesse modelo, o abandono da hipótese de que os dirigentes maximizariam o bem-estar da população invalida o pressuposto de que o socialismo de mercado seria capaz de gerar um sistema de preços eficiente.

Os socialistas de mercado, por outro lado, acreditam que o fracasso do socialismo de mercado real deva ser atribuído à falta de democracia existente nessas experiências concretas. As propostas modernas de socialismo de mercado, porém, supõem democracia. Shleifer e Vishny (1994:169) investigam então como a democracia modifica as conclusões derivadas do modelo acima. Para estes autores, não se pode esperar a busca de eficiência por parte de governos democráticos, tanto nas economias de mercado quanto no socialismo - admitindo que neste último a democracia seja possível. No modelo de voto majoritário, uma transferência da minoria para a maioria tende a ser aprovada mesmo que o ganho para a maioria seja menor do que o custo para a minoria. No modelo de grupos de interesse, por outro lado, os governos também não são pautados por preocupações sobre eficiência, a menos que não haja custos para organizar grupos e pressionar o parlamento. Se alguns grupos tiverem custos menores para se organizar, as decisões políticas refletirão os interesses desses grupos. Embora a democracia não garanta a busca de eficiência nos dois regimes, as distorções seriam bem piores no socialismo (Shleifer e Vishny, 1994:173). Neste, pelo fato de que o estado é relativamente 
muito mais rico do que o estado capitalista, seria mais fácil bancar intervenções ineficientes com propósitos políticos.

A crítica ao socialismo de mercado de Shleifer e Vishny provocou uma reação de Bardhan e Roemer. Os argumentos desses autores foram vistos por Bardhan e Roemer (1994) como um exagero em uma direção oposta: embora não seja verdade que o governo seja completamente desinteressado, também não é verdade que seja exclusivamente composto de agentes egoístas. De qualquer modo, acreditam estes autores que suas propostas lidam satisfatoriamente com o problema de isolar as firmas de indevida interferência governamental. Os mecanismos que limitariam essa interferência, sugerem, poderiam ter o status de garantias constitucionais.

A crítica comportamental ao socialismo feita pela escola da escolha pública (os agentes do governo não são desinteressados), ao contrário da crítica epistemológica austríaca (os agentes do governo não são oniscientes), poderia ser contestada com base na observação de que nada garante que a hipótese de comportamento egoísta seja sempre válida. É possível imaginar sociedades não individualistas, nas quais os agentes se comportariam de outra maneira. De fato, em outra ocasião, Bardhan e Roemer sugerem exatamente isso: "Indeed, it may be the case that the culture of management in a market-socialist economy, with its Weltanschauung of egalitarianism, would be different, at least to some extent, from the culture of capitalist management". (Bardhan e Roemer, 1993:8)

Independentemente da controvérsia sobre se o egoísmo estaria calcado na natureza humana ou não, uma observação pode ser feita a respeito da questão. Como observou Buchanan (1987), trabalhar com a hipótese de agentes egoístas não equivale a afirmar que os agentes de fato assim o sejam, mas sim indagar, como teria feito Adam Smith, sobre que conjunto de instituições impediria que o payoff de um único agente oportunista seja grande o bastante de maneira que seu comportamento passe a se espalhar e eventualmente dominar as relações sociais. Busca-se assim um conjunto de regras cujo bom funcionamento não dependa da perfeição moral de todos os agentes.

Deve-se então investigar a possibilidade de que uma sociedade inspirada em um modelo desenhado com o objetivo de evitar os problemas discutidos acima venha a evoluir na direção de suprimir as 
garantias estabelecidas contra o uso indevido do poder, visto que nessa sociedade existe um estado forte cujo poder poderia tentar um líder não desinteressado. Essa é justamente uma preocupação presente na crítica de Kornai ao socialismo de mercado moderno, para a qual nos voltaremos agora.

Kornai (1993:48), de fato, acredita que é impossível desenhar e fazer valer um contrato entre estado central (principal) e firmas (agentes) que garanta uma alocação eficiente de recursos, como querem os socialistas de mercado. Isso porque seria ingênuo esperar que o processo produtivo seja despolitizado, uma vez que a propriedade pública de fato coloca a economia nas mãos de políticos. Como Shleifer e Vishny, Kornai acredita que os objetivos destes, como crenças ideológicas ou brigas por poder, distorceriam as decisões econômicas. A tentação da burocracia de exercer o poder e não delegá-lo à gerência das firmas seria irresistível.

Kornai (1993:51) ataca também a crença fundamental dos socialistas de mercado de que o problema de agência advindo da separação entre propriedade e gerência no capitalismo seria análogo ao problema das firmas no socialismo de mercado. A analogia se revelaria falsa quando se observa que neste último: a) os objetivos do principal são políticos e não a maximização dos lucros, b) os principais utilizam como ameaça de penalidade polícias políticas e não penalidades financeiras e demissão e c) os agentes não podem trocar de empregador, uma vez que o estado é o único proprietário, mantendo o registro do funcionário em qualquer firma que este esteja. Se o administrador se opuser à burocracia central, suas chances de prosseguir carreiras em outra parte são bastante limitadas. Disso Kornai conclui, seguindo Mises, que seria impossível obter descentralização verdadeira sem propriedade privada. Adicionalmente, com propriedade pública, as firmas nunca seriam abandonadas à sua própria sorte. A propriedade privada seria então condição necessária para uma restrição orçamentária não tênue.

Além da discussão do papel da propriedade privada, Kornai retoma o conceito austríaco (e clássico) de competição, centrado na atividade rival. Kornai (1993: 54) acredita que no SM não haveria livre entrada e saída de firmas, ao contrário do que acreditam os seus defensores. Para Kornai as decisões de entrada e saída seriam tomadas em um ambiente político. Sem livre entrada, continua o autor, 
não ocorreria o processo de seleção natural e a ação competitiva das firmas no sentido de superarem umas às outras. Sem esse processo de seleção natural seria impossível estabelecer um 'contrato' entre o estado (principal) e as firmas (agentes), já que sem competição seria impossível comparar o desempenho das firmas e, portanto, avaliar se o contrato foi cumprido ou não.

Kornai resvala assim em um dos argumentos de Hayek contra o socialismo de mercado: não existem os 'dados' da economia de forma independente do processo competitivo. Embora reconheça a ligação entre suas críticas ao socialismo de mercado moderno e as críticas de Mises e Hayek ao socialismo de mercado antigo, Kornai (1993:63) considera essas últimas como 'palpites brilhantes', baseados na 'visão' dos autores. Mesmo utilizando argumentos austríacos, Kornai não reconhece a teoria de processo de mercado como uma alternativa à luz da qual o socialismo de mercado moderno poderia ser analisado.

Essa postura, naturalmente, é explicada pelas diferenças entre os núcleos duros dos dois programas de pesquisa que dificultaram o diálogo em todas as fases do debate do cálculo. Mas, se abrirmos espaço para a ideia austríaca de que fora do equilíbrio os agentes possam, mesmo na posse do mesmo conjunto de informações objetivas, ter opiniões diferentes sobre o estado dos mercados, de modo que a competição envolva a rivalidade entre planos baseados nessas opiniões conflitantes, não será mais possível ignorar na avaliação do SM moderno as objeções austríacas feitas aos modelos originais.

Isso nos traz de volta ao contraste que fizemos no início do artigo entre a preocupação austríaca com a economia do conhecimento e a preocupação neoclássica com a economia da informação. A leitura da contribuição de Hayek ao debate sob os óculos da segunda abordagem direcionou de fato a discussão para o desenho de mecanismos de incentivos que motivem os agentes a seguir as ordens dos principais. Por outro lado, assumindo-se tal motivação, o problema de saber $o$ que deve ser feito pelos agentes não recebeu devida atenção. Esse problema será central na próxima seção, que trata de uma análise da nova fase do debate, sob o ponto de vista austríaco. 


\section{O Problema do Socialismo de Mercado: Informação ou Conhe- cimento?}

Nos termos da abordagem evolucionária do argumento austríaco que aludimos no início do artigo, para que possamos supor um processo de aprendizado em um sistema econômico complexo, devemos explicar como são geradas as diferentes hipóteses sobre as cambiantes condições econômicas locais (variação), como se dá o processo de correção de hipóteses erradas (seleção), como o conhecimento adquirido é preservado e transmitido (hereditariedade) e como esses elementos se relacionam. Em uma proposta de SM, o processo de aprendizado composto por esses elementos deve pelo menos replicar a complexidade e a riqueza de detalhes encontrados nos mercados reais. Examinemos agora os modelos modernos de SM sob esse ponto de vista.

Em relação à geração de hipóteses empresariais rivais, os modelos em questão limitam a capacidade empreendedora em vários aspectos. Empresas com mais de alguns poucos funcionários não podem unir capacidades para lançar novos projetos em conjunto. Para obter financiamento, uma firma depende exclusivamente de seu banco principal, o que limita a sua capacidade de inovação: os administradores, caso queiram exercer atividade empresarial, devem convencer os funcionários desse único banco de que a ideia é viável ou abandonar o projeto, pois é ilegal convencer poupadores independentes a investir no projeto. Como os bancos são em última análise estatais, é provável que uma concepção central prévia sobre a realidade econômica venha a direcionar a aprovação de crédito em projetos compatíveis com essa concepção. A atividade empresarial nas firmas médias e grandes é então limitada a decisões sobre o uso da quantidade de capital já investida nas mesmas.

Um empresário independente, por sua vez, só pode pôr em prática sua hipótese empresarial se esta for aplicada em pequena escala, já que o esquema permite apenas a livre iniciativa em firmas com um número reduzido de funcionários. Ideias empresariais que dependam de uma escala mínima maior seriam barradas. Essa restrição da proposta, além de limitar a geração de hipóteses empresariais, provavelmente teria um efeito distorcivo na alocação de recursos: caso a avaliação do banco sobre o valor presente dos rendimentos futuros da firma seja superior à do empresário, este tentará artificialmente ex- 
pandir o seu empreendimento a fim de vendê-lo para o setor estatal a esse valor. Se o estado avaliar o empreendimento na outra direção, a firma irá deter a expansão a fim de evitar venda de seus ativos a um valor inferior àquele que considera verdadeiro.

Como a teoria que orienta as propostas se concentra em problemas de informação e não na falibilidade do conhecimento dos agentes, o problema da atividade empresarial é subestimado. Roemer e Bardhan acreditam que a liberdade de estabelecimento de pequenas firmas e o financiamento de laboratórios de pesquisa bastariam para manter a capacidade inovadora na economia. As inovações não dependeriam significativamente do processo de rivalidade entre firmas que se manifesta, por exemplo, em mercados de capital desenvolvidos.

O tratamento exógeno da função empresarial aparece de forma explícita em Yunker (1995), que imagina em sua proposta uma agência denominada National Entrepreneurial Investiment Board encarregada de 'estabelecer novas firmas viáveis e lucrativas'. A atividade empresarial, infere-se dessa sugestão, novamente nada deve à existência de diversidade de opiniões de agentes independentes que possam ter alguma liberdade de apostar em suas ideias.

O outro aspecto das propostas modernas de socialismo de mercado que devemos considerar é a natureza do processo seletivo. Embora seja suposto o mesmo mecanismo de lucros e perdas das economias de mercado, as diferenças entre as instituições destas economias e dos modelos propostos restringem na prática a efetividade desse mecanismo seletivo, visto que se subestima a necessidade do aprendizado empresarial. $\mathrm{Na}$ abordagem austríaca, a bolsa de valores funciona como uma arena na qual se debatem os planos rivais dos empresários. Estes empenham seus recursos em projetos compatíveis com (ou dirigidos por) tais planos. A lucratividade passada das firmas (com ações em bolsa ou não), por sua vez, reflete ao mesmo tempo a sorte e a habilidade do empresário de antever as condições futuras dos mercados, servindo como um teste das ações empresariais de seus dirigentes.

Já na visão de Roemer e Bardhan, a existência de bolsas de valores serve para disciplinar o comportamento dos administradores caso estes não desejem maximizar lucros. O prejuízo funciona como uma ameaça contra comportamentos tais como esforço insuficiente (shir- 
king), e não como uma consequência de erros empresariais. Como o problema do socialismo de mercado é visto em termos de informação assimétrica em relação ao comportamento dos administradores, e não em termos de geração de conhecimento empresarial, desaparecem de cena o processo de eliminação de erros e a consequente variação de renda decorrente disso, como se as ações adequadas a serem tomadas pelas firmas já fossem conhecidas e a economia estivesse automaticamente perto de um equilíbrio estático e tudo o que resta é convencer as pessoas a implementar as ações desejadas.

Mas, a menos que se suponha conhecimento perfeito ou ainda ignorância ótima, os erros são inevitáveis. Nos modelos dos autores, contudo, os agentes nunca fracassam de fato. Um poupador privado nunca perde seus recursos em aplicações erradas, pois administradores profissionais dos fundos mútuos administram seus portfólios. Os fundos mútuos, por sua vez, ao mesmo tempo controlam indiretamente um conjunto pequeno de firmas, de modo a conseguir monitorá-las, e diversificado o bastante para não depender da sorte de qualquer uma dessas firmas. Caso uma firma dê sinais de fracassar, o fundo mútuo e os bancos atuam prontamente sobre os administradores das firmas de forma a rapidamente corrigir o erro.

O que ocorreria, porém, se o erro não for devido a administradores não vigiados o bastante, mas sim for fruto da adoção de planos errados, incompatíveis com a realidade econômica do mercado em questão? Nesse caso, estamos simplesmente deslocando a atividade empresarial da firma para os fundos mútuos. Estes estarão então sujeitos ao fracasso e o estarão de forma mais intensa, pois esse deslocamento da atividade empresarial apresenta o problema de menor uso de informação dispersa e de menor diversidade de opiniões empresárias, já que a atividade empresarial é mais centralizada.

Se os fundos mútuos e os bancos fracassarem, por sua vez, a perda de capital seria muito concentrada, o que tornaria improvável que isso seja politicamente viável. Entra então em cena a síndrome de restrição orçamentária tênue de Kornai: os fundos mútuos seriam salvos pelo governo central e provavelmente haveria grande expansão de crédito como resultado da tentativa de salvá-los. Esse resultado não seria devido à falta de democracia (o que Roemer e Bardhan consideram o problema de agência do público em relação ao estado), mas sim inerente ao regresso infinito existente no modelo: não se 
pode ter um processo de tentativas e erros sem erros, e eliminar a variação na renda dos agentes econômicos transferindo a responsabilidade para instâncias anteriores torna os erros mais graves e de maior magnitude. Como a diminuição de renda advinda do erro é deslocada para instâncias mais amplas, a competição entre os agentes se transfere da esfera econômica para a política, na disputa para se livrar do ônus de arcar com o prejuízo. ${ }^{10}$ Neste ponto a análise da escola de escolha pública complementa a análise austríaca.

Com essa crítica austríaca à nova geração de modelos, concluímos o contraste entre os diversos pontos de vista expostos na retomada do cálculo econômico socialista na década de noventa. Como no restante do debate, as posições irreconciliáveis foram em última análise fruto das diferenças entre os programas de pesquisa que informam os debatedores: para proteger os núcleos duros desses programas, os argumentos rivais são traduzidos para referencial de cada analista, de modo a perder seu significado original. Isso barra o progresso do entendimento via debate. Por outro lado, as mudanças nos cinturões protetores dos programas fizeram com que a discussão explorasse aspectos interessantes do mesmo problema que antes foram ignorados, possibilitando uma melhor compreensão do objeto da controvérsia. Ao salientar as diferenças entre os problemas (de informação e de conhecimento, bem como sobre o significado do postulado de autointeresse) que informam as diferentes abordagens em conflito, esperamos com nosso trabalho contribuir para os argumentos sejam entendidos em seus próprios termos, condição necessária para um verdadeiro avanço no debate.

\section{Referências}

Barbieri, F. Uma História do Debate do Cálculo Econômico Socialista. FEA - Universidade de São Paulo. Tese de doutorado, 2004.

Barbieri, 2006. Filosofia da Ciência como Ferramenta Microeconômica. Belo Horizonte: Nova Economia, vol. 16, n.3, 2006.

Bardhan, P. E Roemer, J.E. Market Socialism: A Case for Rejuvenation, Journal of Economic Perspectives, Vol. 6, No. 3, 1992.

Bardhan, P. E Roemer, J.E. (ed.) Market Socialism: The Current Debate. Oxford: Oxford University Press, 1993.

${ }^{10}$ É curioso notar que Roemer e Bardhan, escrevendo na primeira metade da década de noventa, tomam como modelo o sistema bancário japonês, que, ironicamente, viria a entrar em crise logo em seguida, em grande medida devido ao excesso de créditos concedidos indiscriminadamente. 
Bardhan, P. E. Roemer, J. E. On the Workability of Market Socialism, Journal of Economic Perspectives, Vol. 8, No. 2, 1994.

Bartley, III, W.W. E Radnitzky, G. (eds.) Evolutionary Epistemology, Rationality and the Sociology of Science. La Salle: Open Court, 1987.

Buchanan, J. M. Economics: between predictive science and moral philosophy. Texas A\&M University Press, 1987.

Fleurbaey, M. Economic Democracy and Equality: A Proposal, in Bardhan, P. E Roemer, J. E. (eds.), 1993.

Gossen, H. H. (1983) [1853] The Laws of Human Relations and the Rules of Human Action Derived Therefrom. Cambridge: The MIT Press.

Grossman, S. J. e Stiglitz, J. E. Information and Competitive Price Systems, American Economic Review Vol. 66, No. 2, 1996.

Hayek, F.A. Individualism and Economic Order, Chicago: Chicago University Press, 1980.

Hayek, F.A. The Use of Knowledge in Society in Hayek, F.A. Londres: Econômica, 1945.

Hayek, F.A. Competition as a Discovery Procedure, em New Studies in Philosophy, Politics and Economics. Londres: Routledge, 1978.

Knight, F.H. The Place of Marginalist Economics in a Collectivist System, American Economic Review, Vol. 26, No. 1, 1936.

Kornai, J. The Soft Budget Constraint, Kyklos, Vol 39, No. 1, 1986.

Kornai, J. Market Socialism Revisited, em Bardham e Roemer (ed.), 1993.

Lavoie, D. Rivalry and Central Planning, Cambridge: Cambridge Economic Press, 1985.

Lerner, A.P. "Statics and Dynamics in a Planned Economy", The Economic Journal, Vol. 47, Issue 186, pág. 253-270, 1937.

Levy, D. The Bias in Centrally Planned Prices, Public Choice, Vol. 67, pág. 213-226, 1990.

Roemer. J. E. A Future for Socialism. Cambridge: Harvard University Press, 1994.

Shleifer, A. e Vishny, W. Pervasive Shortages under Socialism, RAND Journal of Economics, vol. 23(2), pages 237-24, 1992.

Shleifer, A. e Vishny, W. The Politics of Market Socialism Journal of Economic Perspectives, vol. 8, n 2, 1994, pg. 165-176.

Soto, J.H. Socialismo, Cálculo Económico y Función Empresarial. Madri: Unión Editorial, 1992.

Soto, J.H. A Escola Austríaca. São Paulo: Instituto Mises Brasil, 2010.

Stiglitz, J. Market Socialism and Neoclassical Economics, in Bardham e Roemer (ed.), 1993.

Stiglitz, J. Whither Socialism? Cambridge: The MIT Press, 1994.

Thomsen, E. Prices and Knowledge. Londres: Routledge,1992.

Weisskopf, T. E. A Democratic Enterprise-Based Market Socialism, in Bardhan e Roemer (eds.), 1993.

Yunker, J.A. Post Lange Market Socialism: an evaluation of profit-oriented proposals, Journal of Economic Issues, Sept., 1995. 